\title{
Biological responses of $T$ cells encapsulated with polyelectrolyte- coated gold nanorods and their cellular activities in a co-culture system
}

\author{
Porntida Wattanakull $^{1} \cdot$ Murray C. Killingsworth $^{2,3} \cdot$ Dakrong Pissuwan $^{1}{ }_{\mathbb{C}}$
}

Received: 1 July 2017/Accepted: 22 September 2017/Published online: 4 October 2017

(c) The Author(s) 2017. This article is an open access publication

\begin{abstract}
Currently, human T cell therapy is of considerable scientific interest. In addition, cell encapsulation has become an attractive approach in biomedical applications. Here, we propose an innovative technique of single-cell encapsulation of human $\mathrm{T}$ cells using polyelectrolytes combined with gold nanorods. We have demonstrated encapsulation of human Jurkat $\mathrm{T}$ cells with poly(sodium 4-styrenesulfonate) (PSS)-coated gold nanorods (PSSGNRs). Other forms of encapsulation, using polyelectrolytes without GNRs, were also performed. After Jurkat $\mathrm{T}$ cells were encapsulated with poly(allylamine hydrochloride) (PAH) and/or PSS-GNRs or PSS, most cells survived and could proliferate. Jurkat $\mathrm{T}$ cells encapsulated with a double layer of PSS-GNR/PAH (PSS-GNR/PAH@Jurkat) showed the highest rate of cell proliferation when compared to 24-h encapsulated cells. With the exception of IL6 , no significant induction of inflammatory cytokines (IL-2, IL-1 $\beta$, and TNF- $\alpha$ ) was observed. Interestingly, when encapsulated cells were co-cultured with THP-1 macrophages, co-cultures exhibited TNF- $\alpha$ production enhancement. However, the co-culture of THP-1 macrophage and
\end{abstract}

Electronic supplementary material The online version of this article (doi:10.1007/s13204-017-0605-8) contains supplementary material, which is available to authorized users.

Dakrong Pissuwan

dakrong.pis@mahidol.ac.th

1 Materials Science and Engineering Program, Multidisciplinary Unit, Faculty of Science, Mahidol University, Bangkok, Thailand

2 Electron Microscopy Laboratory, Sydney South West Pathology Service, NSW Health Pathology, Sydney, Australia

3 Ingham Institute, Sydney, Australia
PSS-GNR/PAH@Jurkat or PSS/PAH@Jurkat did not enhance TNF- $\alpha$ production. No significant inductions of IL-2, IL-1 $\beta$, and IL- 6 were detected. These data provide promising results, demonstrating the potential use of encapsulated PSS-GNR/PAH@Jurkat to provide a more inert $\mathrm{T}$ cell population for immunotherapy application and other biomedical applications.

Keywords Cell encapsulation · Polyelectrolytes · Gold nanorods · Biological activity $\cdot$ Human $\mathrm{T}$ cell therapy

\section{Introduction}

The transplantation of cells or tissues has been applied for treating various human diseases (Bhatia et al. 2005). Unfortunately, when using this technique, transplanted cells can be rejected by the immune system of the body. Immunosuppressant drugs are applied to solve this problem, but these drugs can cause many complications (Uludag et al. 2000). The encapsulation of cells has been developed to avoid immune rejection in cell/tissue transplantation. Furthermore, this technique can be used for other applications such as controlled delivery (Orive et al. 2014), regenerative medicine (Hunt and Grover 2010), and drug delivery (Gurruchaga et al. 2015). There are many approaches that have been used to encapsulate cells, such as, using alginate-poly cationic poly(L-lysine) (PLL) (Uludag et al. 2000), interfacial precipitation (Ai et al. 2003), and coacervation techniques (Kampf 2002). The layer-by-layer (LBL) technique is another attractive approach that can be used for cell encapsulation. This technique provides a well-defined surface, gentle conditions, nanoscale precision, and tuneable multilayer construction (Ai et al. 2003; Franz et al. 2010). Various types

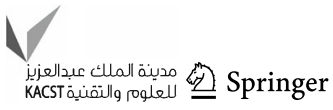


of mammalian cells, such as, human adipose mesenchymal stem cells (Granicka et al. 2014; Hachim et al. 2013), islet cells (de Vos et al. 2014), lymphocytes (Granicka et al. 2014), and human leukemia cells (Borkowska et al. 2014) have been encapsulated using this technique. The LBL encapsulation technique can also be applied for yeasts, fungi, and bacteria (Franz et al. 2010; Diaspro et al. 2002; Fakhrullin et al. 2009).

Human $\mathrm{T}$ lymphocytes play an important role in the immune system and have been used in immunotherapy (Juan et al. 2009; Zhao et al. 2016). Unfortunately, $\mathrm{T}$ lymphocytes from a donor can be activated or interact with cells in the immune system of a recipient, leading to adverse effects (Roncarolo and Battaglia 2007). Therefore, cell encapsulation of $\mathrm{T}$ lymphocytes might help mitigate this problem and increase the efficiency of immunotherapy in many diseases. Recently, gold nanorods (GNRs) have attracted growing interest in biological/biomedical applications. It is known that the surfaces of gold nanorods (GNRs) can be modified with polyelectrolytes through the LBL technique (Pissuwan et al. 2013; Pissuwan and Niidome 2015). This modification can reduce the toxicity of the cationic surfactant (cetyltrimethylammonium bromide; CTAB) that is commonly used to stabilize the surface of GNRs. Because of the excellent optical properties of GNRs, the combination of surface-modified GNRs, with LBL cell encapsulation, should provide substantial benefits. For example, GNRs allow for the use of a variety of characterization techniques including transmission and scanning electron microscopy, Raman spectroscopy, inductively coupled plasma mass spectrometry (ICP-MS), and spectroscopy. Furthermore, GNRs can be conjugated with various biological/chemical molecules. Therefore, rather than encapsulating cells with polymers alone, the deposition of GNRs on the surface layer of polymer-encapsulated cells can provide additional benefits. Firstly, the encapsulated cells that have GNRs fabricated on the layer of cells are able to be easily detected, or tracked, without being faced with photobleaching issues. Next, GNRs provide a high potential for a controlled release application. They can help control release of embedded therapeutic molecules after irradiating under a specific light exposure at tissue window wavelengths leading to heat energy buildup to break the capsule wall. In this work, PSS-coated gold nanorods (PSS-GNRs) were used. These types of GNRs are biocompatible and easy to conjugate with various biological molecules. Finally, the encapsulated T lymphocytes designed for therapeutic or diagnostic purposes can be used to target specific cells.

However, careful consideration is required before designing cells encapsulated with polyelectrolyte-coated gold nanorods for the applications mentioned above. It is necessary to investigate the biological responses of cells after encapsulation. Therefore, the effect of combined encapsulation with polyelectrolytes and GNRs has been assessed to clarify the impact of the coating layer on the cell surface. Furthermore, the downstream effects of this technique on other cell types such as macrophages should be assessed using a co-culture system. For these reasons, we aimed to encapsulate human Jurkat $\mathrm{T}$ cells using the LBL technique. These cells acted as a template for encapsulating two polyelectrolytes: poly(sodium 4-styrenesulfonate) (PSS) and poly(allylamine hydrochloride) (PAH). The final layer on the encapsulated cells consisted of GNRs coated with PSS (PSS-GNRs). A characterization of encapsulated human Jurkat $\mathrm{T}$ cells was performed. To our knowledge, there are only a few reports regarding the encapsulation of T lymphocytes (Pandey et al. 2013) and no reports using GNRs to encapsulate $\mathrm{T}$ lymphocytes. We examined the biological responses of encapsulated cells. To examine the host response to encapsulated human Jurkat $\mathrm{T}$ cells, a co-culture system of human macrophages and encapsulated cells was also utilized. Our proposed model of cell encapsulation and information on biological cellular responses demonstrates the possibility of applying this technique for future biomedical applications.

\section{Materials and methods}

\section{Preparation of poly(styrene sulfonate)-coated gold nanorods}

Commercial GNRs $(\sim 40 \mathrm{~nm}$ in width and $\sim 68 \mathrm{~nm}$ in length) were purchased from Nanopartz ${ }^{\mathrm{TM}}$, Loveland, USA. The preparation of PSS-GNRs was performed by slightly modifying a previously published procedure (Pissuwan et al. 2013). First, PSS-GNRs were prepared by mixing $600 \mu \mathrm{L}$ GNRs with $300 \mu \mathrm{L}$ PSS $\left(M_{W}=70,000\right.$ at a concentration of $2 \mathrm{mg} \mathrm{mL}^{-1}$ dissolved in $0.5 \mathrm{mM} \mathrm{NaCl}$; Sigma Aldrich, Louis, USA) and the mixture was shaken for $30 \mathrm{~min}$ on a shaker at room temperature. Following this, the mixture of PSS and GNRs was centrifuged at $9391 \times g$ for $10 \mathrm{~min}$. Next, the pellet of PSS-GNRs was dispersed in Milli-Q water for use in further experiments. The morphology of the GNRs was examined by transmission electron microscopy (TEM).

\section{Cell culture}

Human Jurkat T cells (ATCC) and THP-1 macrophages were cultured in Roswell Park Memorial Institute (RPMI) 1640 medium supplemented with $10 \%$ fetal bovine serum (FBS) plus $1 \%$ penicillin/streptomycin. Cells were maintained at $37{ }^{\circ} \mathrm{C}$ in a $5 \% \mathrm{CO}_{2}$ incubator. 


\section{Cell encapsulation preparation}

PAH $\left(M_{W}=15,000\right.$; Sigma Aldrich, Louis, USA $)$ was dissolved in $18 \mathrm{mM} \mathrm{CaCl}_{2}$ to have a stock concentration of $2 \mathrm{mg} \mathrm{mL}^{-1}$. Jurkat $\mathrm{T}$ cells at a concentration of $1 \times 10^{6}$ cells $\mathrm{mL}^{-1}$ (in RPMI-1640 medium without FBS) were incubated with $0.05 \mathrm{mg} \mathrm{mL}^{-1} \mathrm{PAH}$ (diluted from the stock solution using FBS-free RPMI-1640 medium) on a shaker for $5 \mathrm{~min}$ at room temperature. Thereafter, the free PAH was removed by centrifugation (6500 rpm, $5 \mathrm{~min}$ ). The cells coated with PAH were named here as PAH@ Jurkat cells. PAH@Jurkat cells were then incubated with $0.1 \mathrm{mg} \mathrm{mL}^{-1}$ PSS (dissolved in FBS-free RPMI-1640 medium) on a shaker for $10 \mathrm{~min}$ at room temperature. Next, the same process mentioned above was used to remove free PSS. To prepare Jurkat cells coated with PSSGNRs (PSS-GNR/PAH@Jurkat cells), PAH@Jurkat cells were firstly prepared and then a $150 \mu \mathrm{L}$ of FBS-free RPMI1640 medium was added into cells. Following this step, $50 \mu \mathrm{L}$ PSS-GNRs $\left(\mathrm{OD}_{604 \mathrm{~nm}} \sim 0.6\right)$ was added into the cell mixture and incubated on a shaker for $15 \mathrm{~min}$ at room temperature. Next, cells were centrifuged to remove free PSS-GNRs. Finally, PAH@Jurkat and PSS-GNR/PAH@Jurkat cells were suspended in RPMI-1640 medium plus $10 \%$ FBS for use in further experiments.

\section{Cell encapsulation characterization}

The successful encapsulation of Jurkat $\mathrm{T}$ cells was confirmed using various techniques.

\section{Fluorescence observation}

Fluorescein isothiocyanate (FITC) and tetramethylrhodamine isothiocyanate (TRITC) dyes (Sigma Aldrich, Louis, USA) were conjugated with PAH by following the protocol published by Winky et al. (2003). The conjugation of PAH to FITC (PAH-FITC) or TRITC (PAH-TRITC) was prepared by dissolving $2 \mathrm{mg}$ FITC or TRITC dye in $250 \mu \mathrm{L}$ dimethylsulphoxide (DMSO). The PAH solution was prepared by dissolving $250 \mathrm{mg}$ PAH in $3 \mathrm{~mL}$ Milli-Q water. The $\mathrm{pH}$ of the $\mathrm{PAH}$ solution was adjusted to 8.0-8.5 using $1 \mathrm{M} \mathrm{NaOH}$. The conjugation of PAH to FITC or TRITC dye was performed by mixing the prepared FITC or TRITC solution $(250 \mu \mathrm{L})$ with $3 \mathrm{~mL}$ PAH solution (Winky et al. 2003). The mixture was then incubated overnight at room temperature in the dark. After incubation, the mixture was dialyzed to remove free dye molecules of FITC or TRITC by a $3.5 \mathrm{kDa}$ molecular weight cut off membrane (Cellu Sep H1, Texas, USA). Finally, the conjugated PAH to dye molecules was lyophilized by a freeze dryer. Standards of PAH solution at different concentrations were prepared to measure the optical density at $212 \mathrm{~nm}$. This standard was used to calculate the amount of PAH in PAHdye conjugates.

To confirm the encapsulation of Jurkat $\mathrm{T}$ cells into a PAH layer (PAH@Jurkat), unencapsulated Jurkat T cells $\left(1 \times 10^{6}\right)$ cells were added into a cell culture dish coated with $0.01 \%$ poly-L-lysine (PLL). Cells were then incubated in a cell incubator for $1 \mathrm{~h}$ and washed once with FBS-free RPMI 1640 medium. After washing, $500 \mu \mathrm{L}$ PAH-FITC conjugates (containing $0.05 \mathrm{mg} \mathrm{mL}^{-1} \mathrm{PAH}$ ) were added into a dish and incubated in the dark for $5 \mathrm{~min}$ at $37^{\circ} \mathrm{C}$. Thereafter, the solution of PAH-FITC conjugates was removed. Next, the cells attached to the dish were washed twice with FBS-free RPMI-1640. In the cell fixation process, the cells attached onto the dish were fixed with $3 \%$ paraformaldehyde in PBS for $15 \mathrm{~min}$ at $4{ }^{\circ} \mathrm{C}$ and washed 2 times with cold PBS. Then, cold PBS was added. A green fluorescent signal was observed under the fluorescence microscope. To confirm whether the double layers of polyelectrolytes formed on the surface of encapsulated Jurkat cells (PSS/PAH@Jurkat cells), the preparation of Jurkat cells was prepared as mentioned above. For the process of encapsulation, cells were first encapsulated with $0.05 \mathrm{mg} \mathrm{mL}^{-1} \mathrm{PAH}$ and then washed. After this, cells were encapsulated with $0.1 \mathrm{mg} \mathrm{mL}^{-1}$ PSS for $10 \mathrm{~min}$ at $37{ }^{\circ} \mathrm{C}$. Thereafter, the PSS/PAH@ Jurkat cells were washed and stained with $500 \mu \mathrm{L}$ PAH-TRITC conjugates (containing $0.05 \mathrm{mg} \mathrm{mL}^{-1} \mathrm{PAH}$ ) under dark conditions for $5 \mathrm{~min}$ at $37^{\circ} \mathrm{C}$. Then, cells were washed and observed under a fluorescent microscope. All washing and encapsulating processes were performed using the same approach mentioned earlier. The confirmation of PSSGNR/PAH@Jurkat cell preparation was performed using a similar process to that described for PSS/PAH@Jurkat cells. Cells stained with fluorescent dyes $\left(\sim 5 \mu \mathrm{g} \mathrm{mL}{ }^{-1}\right.$ for $5 \mathrm{~min}$ ) alone were also prepared as a control sample.

\section{Transmission electron microscopy (TEM)}

PSS-GNR/PAH@Jurkat cells were fixed with $2.5 \%$ glutaraldehyde (in $0.1 \mathrm{M}$ sodium cacodylate buffer (SCB) pH7.4 overnight). The post-fixation was performed by fixing encapsulated and unencapsulated cells with $1.0 \%$ osmium tetroxide $\left(\mathrm{OsO}_{4}\right)$ for $4 \mathrm{~h}$ at room temperature. Thereafter, the cell samples were dehydrated in $30,50,70$, 80 , and $90 \%$ ethanol, respectively. This process was performed twice (15 min soaking time at each concentration of ethanol). After this, cells were soaked in $100 \%$ ethanol 4 times for 15 min each time. Following dehydration, cells were embedded in araldite resin and cell samples were cut to a thickness of $90 \mathrm{~nm}$ and stained with $2 \%$ uranyl acetate followed by lead citrate. The samples were then observed under TEM at $80 \mathrm{kV}$ (FEI Morgagni 268D, Netherlands). Unencapsulated cells were prepared as a control. To 
observe the morphology of PSS-GNRs, a solution containing PSS-GNRs was dropped on a copper grid. The sample was dried and then observed under TEM.

\section{Scanning electron microscope (SEM)}

Encapsulated and unencapsulated cells were pre-fixed with $2.5 \%$ glutaraldehyde overnight. Following this, cells were fixed with $1 \% \mathrm{OsO}_{4}$ for $1 \mathrm{~h}$ for post-fixation. Next, cells were consequently dehydrated by soaking in 50, 60, 70, 80, 90, and $100 \%$ ethanol for 15 min (Heckman et al. 2007). The critical point drying (CPD) approach was used to dehydrate biological tissues before examination by SEM. This CPD technique can help avoid damaging the surface structure of cell samples. First, cell samples were dehydrated in ethanol. After dehydration, cell samples were then placed into a CPD chamber. Then, the chamber was sealed and cooled down to $-10{ }^{\circ} \mathrm{C}$. Next, the temperature was adjusted to $40{ }^{\circ} \mathrm{C}$ and the pressure was slowly increased to $80-120 \mathrm{kgf} \mathrm{cm}^{-2}$. This condition is a $\mathrm{CO}_{2}$ critical point. It is important to carefully monitor the temperature and the pressure to avoid sample damage. The samples were removed from the chamber when the pressure dropped to $0 \mathrm{kgf} \mathrm{cm}^{-2}$. Finally, the cell samples were observed under SEM (Bray 2000).

\section{Zeta potential measurement}

Encapsulated cells (PAH@Jurkat cells, PSS@Jurkat cells, PSS/PAH@Jurkat cells, and PSS-GNR/PAH@ Jurkat cells) at a concentration of $1 \times 10^{6}$ cells mL ${ }^{-1}$ were dispersed in FBS-free RPMI-1640 medium. Zeta potential values of encapsulated and unencapsulated Jurkat $\mathrm{T}$ cells and PSSGNRs were determined by DLS (Malvern, Worcester, UK).

\section{Gold element analysis by ICP-MS}

Encapsulated and unencapsulated Jurkat $\mathrm{T}$ cells at a concentration of $1 \times 10^{6}$ cells per tube were lysed using $250 \mu \mathrm{L}$ lysis buffer [10\% tween-20 dissolved in phosphate buffer saline (PBS)]. Cells were sonicated for $30 \mathrm{~min}$ to destroy the cell membrane. After sonication, cells were digested in a digest buffer $(3 \mathrm{~mL} 65 \% \mathrm{HCl}$ mixed with $1 \mathrm{~mL} 6 \% \mathrm{H}_{2} \mathrm{O}_{2}$ ) with overnight incubation in the dark inside a fume hood. The aqua regia (a $3: 1$ ratio of $\mathrm{HCl}$ to $\mathrm{HNO}_{3}$ ) was prepared. Thereafter, $3 \mathrm{~mL}$ aqua regia was added into cell samples and incubated for $2 \mathrm{~h}$ (Kim et al. 2010). Finally, the cell samples were adjusted to a volume of $100 \mathrm{~mL}$ using Milli-Q water. The final concentration of aqua regia in the sample was $5 \%$ of the total volume of the sample. A standard gold chloride solution (containing 5\% aqua regia) at concentrations of $0,0.2,0.5,1.0,2.0,5.0$, 10.0, and $20.0 \mu \mathrm{g} \mathrm{L}^{-1}$ (ppb) was prepared.

\section{Cell viability}

Different types of encapsulated Jurkat $\mathrm{T}$ cells at a concentration of $1 \times 10^{5}$ cells per well were added into a 96-well plate. Then, encapsulated cells were cultured for $24 \mathrm{~h}$ in a $5 \% \mathrm{CO}_{2}$ incubator. The cell viability of encapsulated cells was directly determined using a CellTiter-Glo luminescent cell viability assay (Promega, Madison, USA). The measurement was performed following the manufacturer's instructions. The luminescent signals were detected and used for calculation of the relative cell viability (\%) expressed as a percentage relative to unencapsulated cells. The cell viability of Jurkat $\mathrm{T}$ cells after encapsulation was also measured immediately.

\section{Cell proliferation}

Different encapsulated cells were seeded into a 96 -well plate (at a concentration of $1 \times 10^{4}$ cells per well). Cells were incubated in a cell incubator for 24,48 , and $72 \mathrm{~h}$, respectively. Following the incubation, a CellTiter 96 AQueous one solution cell proliferation assay (Promega, Madison, USA) $(20 \mu \mathrm{L})$ was used to detect cell proliferation. This process was performed following the manufacturer instructions. Unencapsulated cells were also prepared as a control.

\section{Enzyme-linked immunosorbent assay (ELISA)}

The release of proinflammatory cytokines (IL-6, IL-2, IL$1 \beta$, and TNF- $\alpha$ ) was measured using an ELISA kit (Biolegend, San Diego, USA). Different encapsulated cells were seeded into a 96-well plate $\left(1 \times 10^{5}\right.$ cells per well $)$. Cells were incubated for 5 and $24 \mathrm{~h}$ in a cell incubator. After incubation, the supernatant of cells was collected to analyze proinflammatory cytokines.

\section{Co-culture system}

A co-culture of THP-1 macrophages and encapsulated Jurkat $\mathrm{T}$ cells was prepared. The macrophages at a concentration of $5 \times 10^{4}$ cells per well were added into a 96-well plate and were cultured for $24 \mathrm{~h}$ in a $5 \% \mathrm{CO}_{2}$ incubator. After culturing of THP-1 macrophages, the encapsulated Jurkat $\mathrm{T}$ cells at a concentration of $5 \times 10^{4}$ cells per well were added into a 96-well plate containing cultured macrophage cells. The cells were co-cultured for $24 \mathrm{~h}$. After co-culturing for $24 \mathrm{~h}$, the supernatants were collected to analyze proinflammatory cytokines.

\section{Statistical analysis}

The statistical analysis was performed by using GraphPad Prism software Version 5.0 (GraphPd Inc.). ANOVA and 
Tukey-Kramer tests were used for statistical significant analysis at $P \leq 0.01$.

\section{Results and discussion}

\section{Confirmation of cell encapsulation}

To prove the encapsulation of Jurkat T cells in PAH, PSS/ $\mathrm{PAH}$, or PSS-GNR/PAH, numerous techniques were utilized.

First, the zeta potentials of different encapsulated Jurkat $\mathrm{T}$ cells were measured. Measured cells were dispersed in FBS-free RPMI-1640 for all measurements. The zeta potential value of unencapsulated Jurkat $\mathrm{T}$ cells was $-14.3 \pm 0.2 \mathrm{mV}$. However, when cells were encapsulated with PAH (PAH@Jurkat cells), the zeta potential value changed to $-9.7 \pm 0.2 \mathrm{mV}$. The low negative number of zeta potential value confirms that the cationic polyelectrolyte (PAH) could form a layer on the surface of the Jurkat T cells. When PAH@Jurkat cells were encapsulated with PSS-GNRs (zeta potential $\sim-16.6 \pm 0.7 \mathrm{mV}$ ), the zeta potential of PSS-GNR/PAH@Jurkat cells dropped to have a lower negative value at $-11.3 \pm 0.4 \mathrm{mV}$. The change in zeta potential value clearly indicates that Jurkat $\mathrm{T}$ cells were encapsulated in PAH or PSS-GNR/PAH. Our results were similar to previous works that investigated the zeta potential values of mammalian cells coated with different polymers (Zhao et al. 2016; Pandey et al. 2013; Bondar et al. 2012). As can be seen, PAH@ Jurkat cells had a weak negative value of zeta potential $(-9.7 \pm 0.2 \mathrm{mV})$ and the zeta potential value altered to have a further negative value after encapsulating Jurkat $\mathrm{T}$ cells with PSSGNRs. The mechanism underlying the interaction in this case is unclear. We shall not discuss this in further detail, but rather mention that the charge densities of polyelectrolytes and the concentration of the ions could play a major role here. And, available results of this study strongly suggest that PSS-GNRs could modify the surface of PAH@Jurkat cells resulting in changing of zeta potential values. The binding of a weak negative charge on the cell surface to negatively charged polymers was also reported (Zhao et al. 2016). In the case of PSS/PAH@Jurkat cells, the zeta potential was more negative $(-21.1 \pm 0.4)$ than that of PSS-GNR/PAH@Jurkat cells $(-11.3 \pm 0.4)$. This could be caused by the amount of PSS formed on PSSGNRs used in cell encapsulation, which should be less than that formed after using PSS alone. As expected, Jurkat T cells directly encapsulated in PSS had a similar zeta potential value $(-14.6 \pm 0.2)$ to unencapsulated cells $(-14.3 \pm 0.2)$. This implies that PSS could not bind well to Jurkat $\mathrm{T}$ cells through the same negative charge interaction of PSS and the cell membrane.

The presence of fluorescent dyes attached on PAH was used to confirm the cell encapsulation. There was no fluorescence signal detected in unencapsulated Jurkat $\mathrm{T}$ cells stained with FITC alone (Fig. 1a). However, FITC-positive cells were found in PAH-FITC@ Jurkat cells (Fig. 1b). This indicates that cells were encapsulated with PAH. PSS/ PAH@Jurkat cells stained with PAH-TRITC showed the red fluorescent signal (Fig. 1c). This confirms that PAHTRITC could stain the cells through the PSS outer layer shielding on the Jurkat $\mathrm{T}$ cells. A similar result was also found in PSS-GNR/PAH@Jurkat cells (Fig. 1d). The negative control was prepared by staining PAH@Jurkat cells with PAH-TRITC. There was no presence of a red fluorescent signal. This result indicates that the same polyelectrolytes could prevent the binding between $\mathrm{PAH}$ and PAH-TRTIC on the cell surfaces (Fig. 1e).

We also observed the morphology of Jurkat $\mathrm{T}$ cells by SEM. When compared to unencapsulated cells, the appearance of a smooth surface was detected on
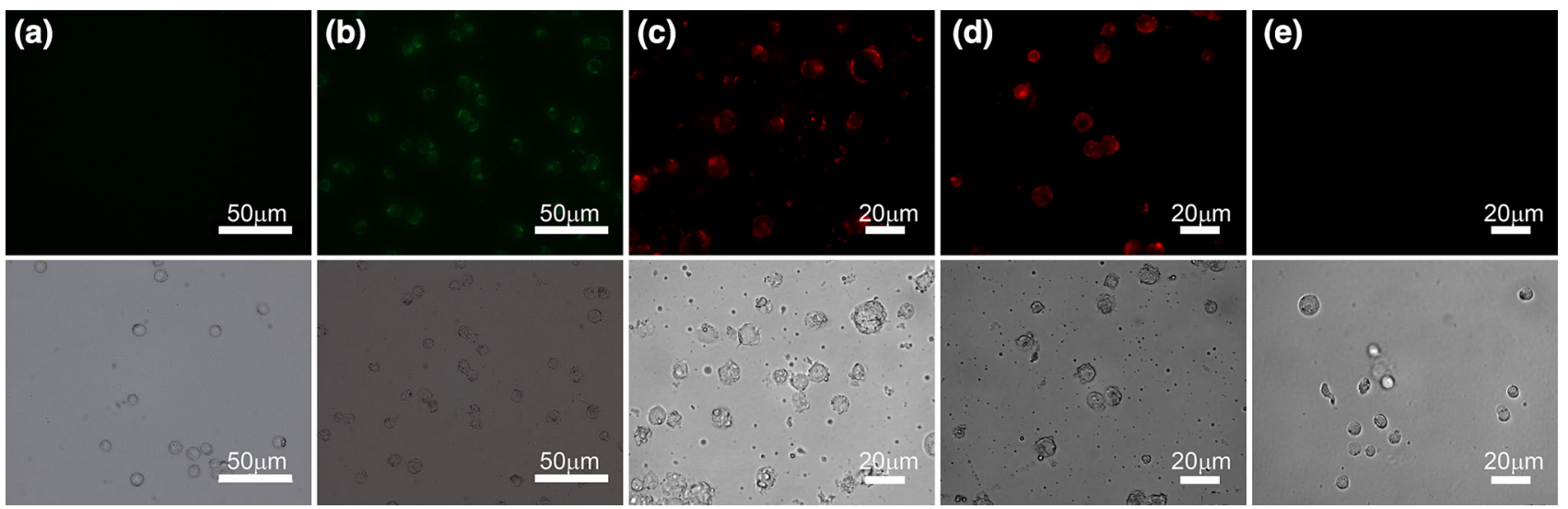

Fig. 1 Images of unencapsulated Jurkat $\mathrm{T}$ cells stained with FITC alone (a), PAH-FITC@Jurkat cells (b), PSS/PAH@Jurkat cells stained with PAH-TRITC (c), PSS-GNR/PAH@Jurkat cells stained with PAH-TRITC (d), and PAH@Jurkat cells with PAH-TRITC (e). The images were captured under bright field and fluorescent modes of a fluorescent microscope 
Fig. 2 SEM images of unencapsulated (a) and encapsulated (PSS-GNR/ PAH@Jurkat) Jurkat T cell (b)
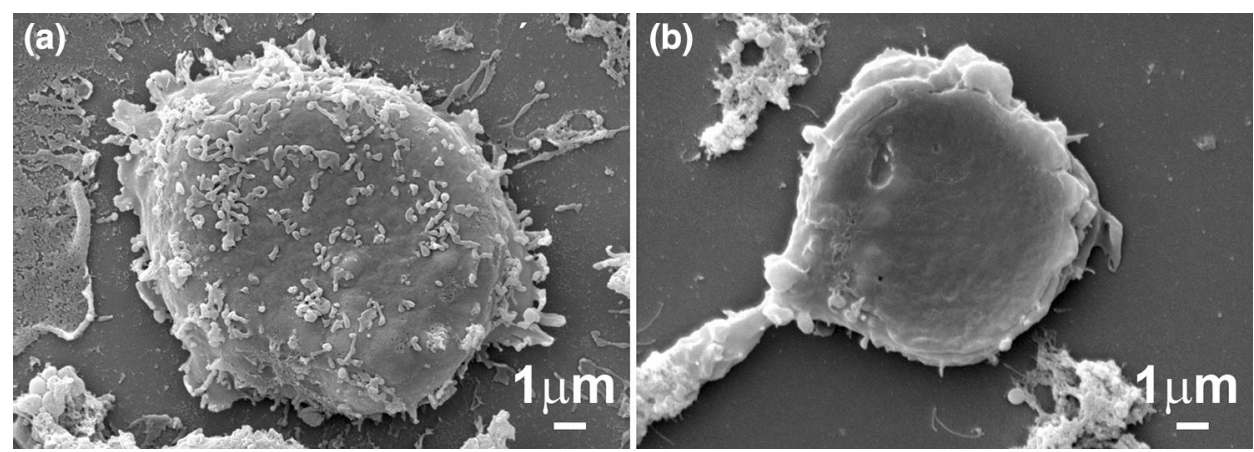

encapsulated cells (PSS-GNR/PAH@Jurkat cells) (Fig. 2b). However, the surfaces of unencapsulated cells had abundant microvilli (Fig. 2a). Our results are consistent with the previous work published by Zhao et al. (2016) that used chitosan and alginate to conduct a conformal encapsulation of $\mathrm{T}$ cells.

All approaches used for confirming the encapsulation of Jurkat $\mathrm{T}$ cells showed that the cells were successfully encapsulated through a layer-by-layer technique. The cationic PAH was shielded on the negative charge of the Jurkat T cell membrane. The second layer of PSS or PSSGNRs was formed surrounding each cell. Overall results from zeta potential measurement, fluorescent observation, and SEM demonstrated the formation of different encapsulated Jurkat T cells (PAH@Jurkat, PSS/PAH@Jurkat, and PSS-GNR/PAH@Jurkat cells).

\section{Investigation of GNRs in PAH/PSS-GNR@ Jurkat cells}

The ICP-MS approach was used to confirm whether PAH@Jurkat cells could be shielded by PSS-GNRs. The TEM image of PSS-GNRs is shown in Fig. 3. The data from ICP-MS showed a significant presence of gold $\left(64.3 \pm 7.7 \mu \mathrm{g} \mathrm{L}^{-1}\right)$ found in PSS-GNR/PAH@Jurkat cells (Fig. 3). The amount of gold observed provides evidence that PSS-GNRs (negatively charged surface) were shielded on the surface of PAH@Jurkat cells (positively charged cell surface) through the opposite charges of their surfaces. This result strongly indicates that a PSS-GNR layer formed on Jurkat $\mathrm{T}$ cells. The very small content of gold detected in PSS-GNR@Jurkat cells $\left(1.8 \pm 0.1 \mu \mathrm{g} \mathrm{L}^{-1}\right)$ could occur due to non-specific binding of PSS-GNRs to cells.

Since the ICP-MS cannot perceive the difference between GNRs deposited on the cell surface and internalized GNRs, TEM was used to evaluate how GNRs were positioned on encapsulated Jurkat $\mathrm{T}$ cells. With TEM images, we found that PSS-GNRs were only located on the cell surface of Jurkat $\mathrm{T}$ cells encapsulated PAH layers (Fig. 4c, red arrow). This strongly indicates that PSS-

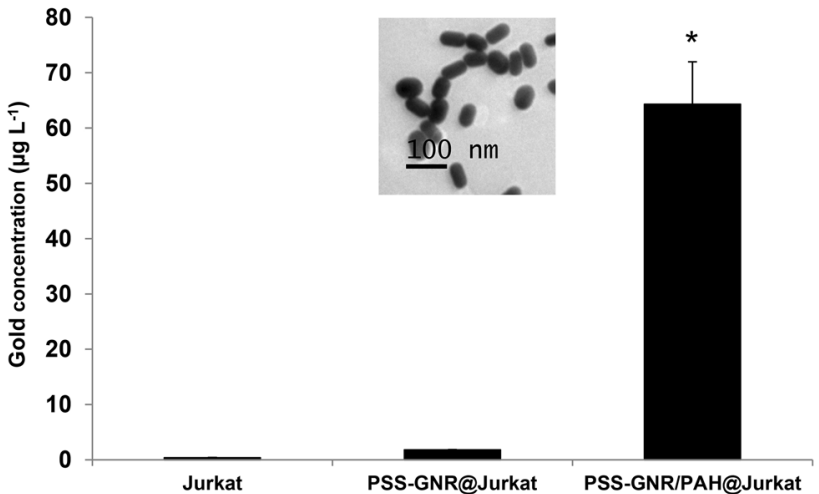

Fig. 3 The amount of gold detected in Jurkat T cells using the ICPMS technique. *Significant difference in gold concentration at $P<0.01$ compared with unencapsulated Jurkat $\mathrm{T}$ cells (Jurkat). Statistical analysis was performed by Tukey-Kramer test $(n \geq 3)$. The TEM image shows the morphology of PSS-GNRs

GNRs only attached to the layer of PAH and did not internalize inside Jurkat $\mathrm{T}$ cells (Fig. 4c). It was reported by Fakhrullin et al. that the polyelectrolyte layer can act as a glue to attach metal nanoparticles and block nanoparticle translocation into the cells (Fakhrullin et al. 2012). As expected, there were no PSS-GNRs located on the cell surface, nor inside Jurkat T cells encapsulated with PSS/ PAH (PSS/PAH@Jurkat cells; Fig. 4b) and unencapsulated Jurkat $\mathrm{T}$ cells (Fig. 4a). An excellent review article by Dykman and Khlebtsov (2014) has shown the effect of gold nanoparticles and their interaction with mammalian cells through cellular endocytosis. Our results here provide evidence that the PAH layer encapsulating on the cell surface might block the cellular uptake of PSS-GNRs through this endocytic pathway.

\section{Cell viability and cell proliferation of unencapsulated and encapsulated Jurtkat cells}

To investigate whether the encapsulating layers affect the cell viability, we measured the cell viability at 0 and $24 \mathrm{~h}$ after cultivation of unencapsulated Jurkat $\mathrm{T}$ cells, PAH@Jurkat cells, PSS/PAH@Jurkat cells, and PSS-GNR/ 

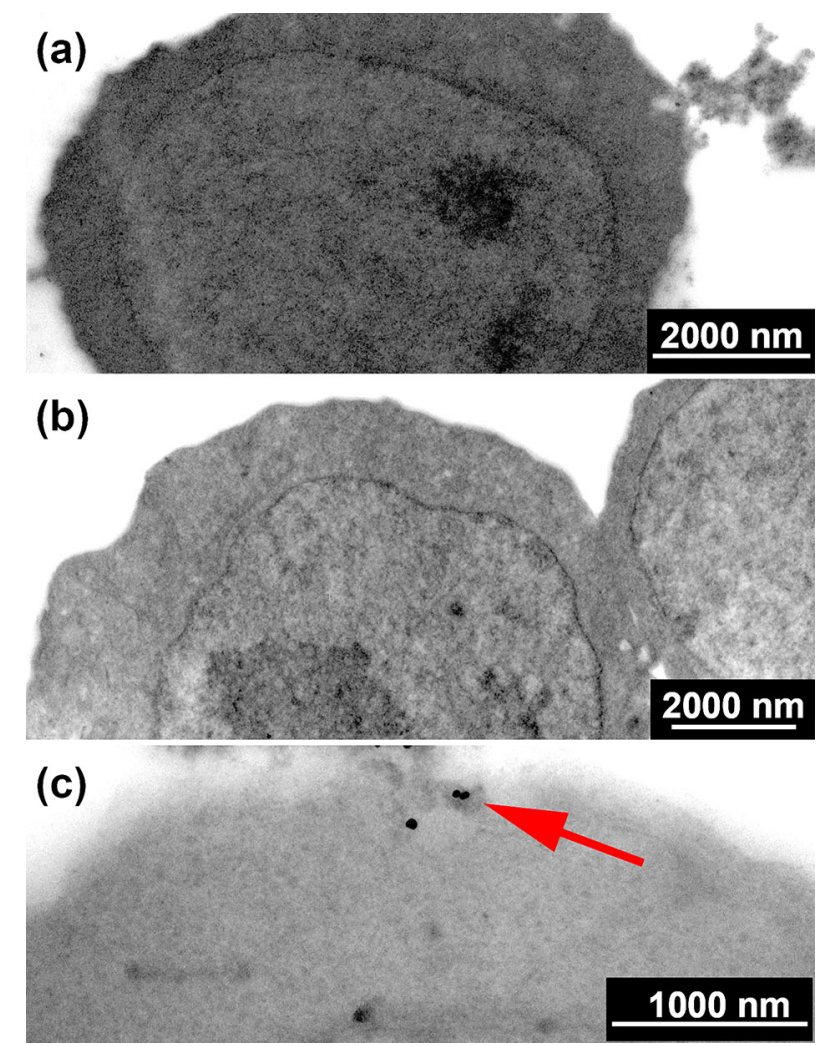

Fig. 4 TEM images of unencapsulated Jurkat $\mathrm{T}$ cells (a), PSS/ PAH@Jurkat (b), and PSS-GNR/PAH@Jurkat cells (c). PSS-GNRs are located (arrow) at the cell membrane of PSS-GNR/PAH@Jurkat cells

PAH@Jurkat cells, using the CellTiter-Glo assay. This technique measured viable cells from the content of adenosine-5'-triphosphate (ATP). After encapsulation, the cell viability of PAH@Jurkat cells, PSS/PAH@Jurkat cells, and PSS-GNR/PAH@Jurkat cells was measured immediately $(0 \mathrm{~h})$. The relative cell viabilities, based on that of unencapsulated cells of PAH@Jurkat cells, PSS/PAH@ Jurkat cells, and PSS-GNR/PAH@Jurkat cells, were $\sim 94.4 \pm 0.3 \%, 90.8 \pm 1.2 \%$, and $96.7 \pm 0.9 \%$, respectively (Fig. 5a). Significant reductions $(P<0.01)$ in cell viability were observed in encapsulated PAH@Jurkat and PSS/PAH@Jurkat cells when compared with unencapsulated cells. The lowest cell viability was detected in PSS/PAH@Jurkat cells. The cell viability after 24-h cultivation of Jurkat $\mathrm{T}$ cells encapsulated with different forms was also measured. It showed that the cell viability of all encapsulated cells significantly decreased $(P<0.01)$ to around $8-15 \%$ depending on the encapsulation method.

Similar to the cell viability at $0 \mathrm{~h}, \mathrm{PSS} / \mathrm{PAH} @$ Jurkat cells at $24 \mathrm{~h}$ showed the lowest percentage of cell viability at $85.3 \pm 0.7 \%$ (Fig. 5b). The cell viabilities of PSS-GNR/ PAH@Jurkat and PAH@Jurkat were 87.0 $\pm 0.5 \%$ and
$91.5 \pm 0.6 \%$, respectively (Fig. 5b). Although the results indicate that the metabolic activity of encapsulated cells was still active after culturing for $24 \mathrm{~h}$, it seems that the number of layers could influence cell viability. Cells encapsulated with a layer of PAH (PAH@Jurkat cells) had a higher cell viability than cells encapsulated with two layers (PSS/PAH@Jurkat and PSS-GNR/PAH@Jurkat cells) after 24-h cultivation. The reason for this could be that there was a higher limitation of nutrient and waste diffusion through cells in cells encapsulated with two layers than that of encapsulation with one layer.

As reported in the review paper (Antipov and Sukhorukov 2004), a higher layer number could lead to a lower amount of penetrated molecules. When compared to the cell viability between PSS/PAH@Jurkat and PSS-GNR/ PAH@Jurkat cells, there was no significant difference in cell viability $(P \leq 0.01)$. Furthermore, cell proliferation was determined gain more information on the metabolic function of cells after encapsulation. Unlike cell viability assay that is normally used to determine the ratio of live and dead cells, it is well known that cell proliferation assay can be used to monitor the growth rate and metabolic activity of cells.

CellTiter $96^{\circledR}$ AQueous One Solution cell proliferation assay was used to measure cell proliferation by measuring metabolic activity of cells through the reduction of MTS tetrazolium (3-(4,5-dimethylthiazol-2-yl)-5-(3-carboxymethoxyphenyl)-2-(4-sulfophenyl)-2H-tetrazolium compounds. We found that cell proliferation of PAH@ Jurkat，PSS/PAH@Jurkat，PSS-GNR/PAH@Jurkat，and Jurkat $\mathrm{T}$ cells was increased when we increased the culturing time from $24 \mathrm{~h}$ to 48 and $72 \mathrm{~h}$, respectively (Fig. 6). This indicates that the encapsulation of cells, using our approach here, could influence the growth rate of Jurkat cells. However, cell proliferation of unencapsulated Jurkat $\mathrm{T}$ cells was much higher than that of encapsulated cells.

The relative growth rates of unencapsulated Jurkat $\mathrm{T}$ cells at 48 and $72 \mathrm{~h}$ were increased $\sim 1.4-$ and 2.3-fold, respectively, above unencapsulated Jurkat $\mathrm{T}$ cells cultured for $24 \mathrm{~h}$. Around a 1.3-fold increase in the proliferation rate of PSS/PAH@Jurkat and PSS-GNR/PAH@ Jurkat cells cultured for $48 \mathrm{~h}$ was detected as compared to encapsulated Jurkat cells after $24 \mathrm{~h}$ culture. The proliferation rate of PAH@Jurkat at $48 \mathrm{~h}$ was $\sim 1.1$-fold increased as compared to at $24 \mathrm{~h}$ culture. At $72-\mathrm{h}$ culture, the increase in proliferation rate of all encapsulated Jurkat $\mathrm{T}$ cells ( 1.4-1.6-fold) was lower than that of unencapsulated Jurkat $\mathrm{T}$ cells $(\sim 2.3$-fold $)$ when compared to 24 -h culture of each cell condition (Fig. 6). The relative proliferating cell percentages of PAH@Jurkat, PSS/PAH@Jurkat, and PSS-GNR/PAH@Jurkat cells at $24 \mathrm{~h}$ significantly decreased from $100 \%$ (of unencapsulated Jurkat T cells) to $\sim 71.9 \pm 1.7 \%, \quad 56.8 \pm 1.1 \%, \quad$ and $\quad 50.2 \pm 1.5 \%$,

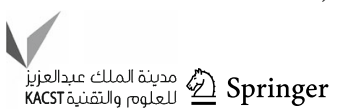


Fig. 5 Cell viability of different encapsulated Jurkat $\mathrm{T}$ cells at $0 \mathrm{~h}(\mathbf{a})$ and $24 \mathrm{~h}$ (b) compared with unencapsulated Jurkat $\mathrm{T}$ cells. * Significant difference in cell viability at $P<0.01$ compared with unencapsulated Jurkat $\mathrm{T}$ cells (Jurkat). Statistical analysis was performed by Tukey-Kramer test $(n \geq 9)$
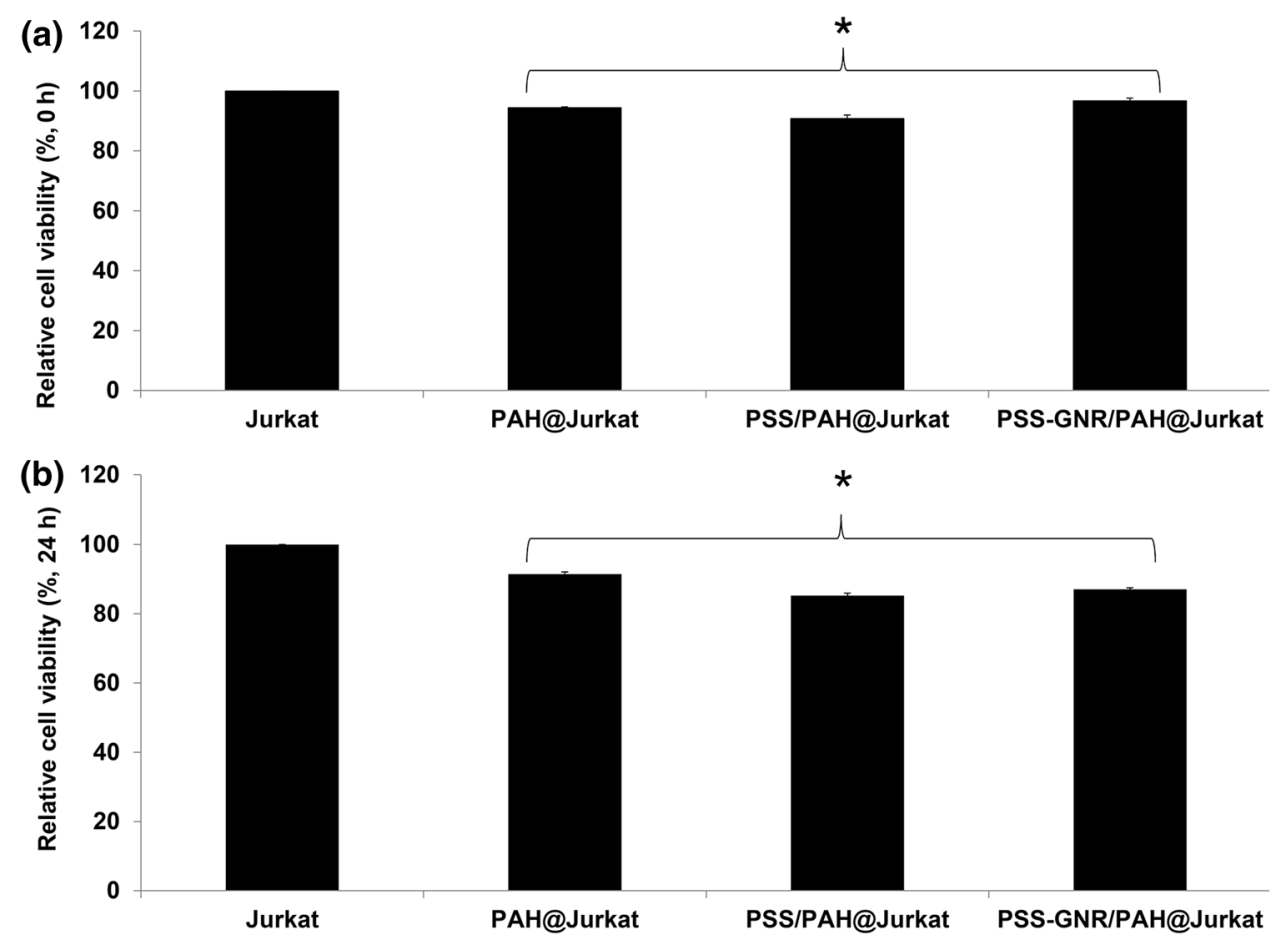

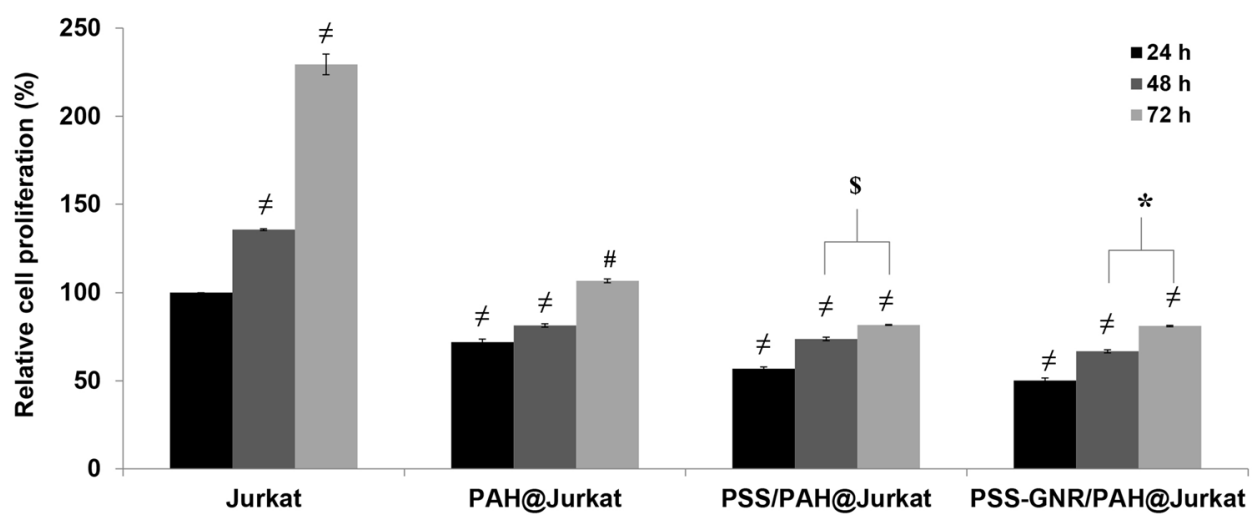

Fig. 6 Cell proliferation of unencapsulated Jurkat $\mathrm{T}$ cells and encapsulated Jurkat $\mathrm{T}$ cells at 24,48 , and $72 \mathrm{~h}$. The percentage of cell proliferation is a mean value of cell proliferation relative to the control (unencapsulated Jurkat $\mathrm{T}$ cells cultured for $24 \mathrm{~h}$ ). ${ }^{\neq}$Significant difference in cell proliferation at $P<0.01$ compared with unencapsulated Jurkat $\mathrm{T}$ cells (Jurkat) at $24 \mathrm{~h}$. " Significant difference in cell

respectively. A significant decrease in proliferation rate of PAH@Jurkat, PSS/PAH@Jurkat, and PSS-GNR/PAH@ Jurkat cells cultured for 48 and $72 \mathrm{~h}$ was also detected as compared to unencapsulated Jurkat $\mathrm{T}$ cells $(P<0.01)$.

At 72 h, PSS-GNR/PAH@ Jurkat cells had the highest increase in growth rate ratio $(\sim 1.6$-fold increase) among all types of encapsulated Jurkat $\mathrm{T}$ cells compared to a 24-h culture of encapsulated cells (PSS-GNR/ PAH@Jurkat) (Fig. 6). The reason that encapsulated cells could proliferate could be a result of the mild layerby-layer processing technique. In our case, it appears proliferation at $P<0.01$ compared with encapsulated PAH@Jurkat cells at $24 \mathrm{~h} .{ }^{\$}$ Significant difference in cell proliferation at $P<0.01$ compared with encapsulated PSS/PAH@Jurkat cells at $24 \mathrm{~h}$. *Significant difference in cell proliferation at $P<0.01$ compared with encapsulated PSS-GNR/PAH@Jurkat cells at 24 h. Statistical analysis was performed by Tukey-Kramer test $(n \geq 6)$

that the charge density of PAH, PSS, and PSS-GNRs might have no major effect on cell proliferation. This might be due to the low concentration of PAH, PSS, and PSS-GNRs used for cell encapsulation. Although encapsulated cells could proliferate, it seems that the encapsulating layer could reduce the rate of proliferation when compared to unencapsulated Jurkat T cells. This could have occurred due to the effect of the encapsulating layer that is possibly impacting on the diffusion rate of molecules that pass through encapsulated cells (Cook et al. 2013). 
Inflammatory cytokine responses of unencapsulated and encapsulated Jurkat $\mathbf{T}$ cells

T cells can produce inflammatory mediators such as IL-6 and TNF- $\alpha$ (Wang et al. 2006). However, high secretions of IL-6 and TNF- $\alpha$ (Wang et al. 2006) can lead to several diseases such as cystic fibrosis (Stecenko et al. 2001), autoimmune disease, and chronic inflammatory proliferative disease (Ishihara and Hirano 2002). Hence, we investigated the secretion of these cytokines from encapsulated and unencapsulated Jurkat cells. IL-2 is a lymphokine that plays an important role in maintaining activated $\mathrm{T}$ cell proliferation (Pawelec et al. 1982). Therefore, we evaluated whether different encapsulations applied in our study affected the secretion of IL-2 by Jurkat T cells. Besides IL-6, TNF- $\alpha$, and IL-2, we also investigated the secretion of IL-1 $\beta$, another cytokine involved in inflammation induction (Tang et al. 2012).

The production of cytokines and lymphokines by encapsulated and unencapsulated Jurkat $\mathrm{T}$ cells was investigated at 5 and $24 \mathrm{~h}$ after cell encapsulation. Unencapsulated Jurkat cells were used as a control sample in our study (Fig. 7). When compared to unencapsulated Jurkat $\mathrm{T}$ cells, the levels of TNF- $\alpha$ and IL-1 $\beta$ at $5 \mathrm{~h}$ secreted by PAH@Jurkat, PSS/PAH@Jurkat, and PSS-GNR/PAH@ Jurkat cells were similar to unencapsulated Jurkat $\mathrm{T}$ cells (Fig. 7a, c). This indicates that the single layer $(\mathrm{PAH})$ or the double layer (PSS/PAH and PSS-GNR/PAH) used for encapsulation of Jurkat $\mathrm{T}$ cells had no effect on TNF- $\alpha$ and IL-1 $\beta$ induction. Similar results were also observed in TNF- $\alpha$ production at $24 \mathrm{~h}$. However, in the case of IL-1 $\beta$, a significant IL-1 $\beta$ reduction was found in PAH@Jurkat cells after treating for $24 \mathrm{~h}(P<0.01)$. The reason for this is uncertain. However, it is a possibility that some IL- $1 \beta$ molecules might not be able to pass through the PAH layer. The zeta potential of PAH@Jurkat cells was less negative than other encapsulating formats, and this could lead to different binding of PAH at the outer layer of cells to other molecules in cell culture media. This binding possibly affected IL-1 $\beta$ release by blocking the diffusion of IL-1 $\beta$. A decrease in IL-2 levels was found in all encapsulated cells after culturing for $5 \mathrm{~h}$. A significant reduction in IL-2 was detected in all encapsulated cells after cells were encapsulated and cultured for $24 \mathrm{~h}(P<0.01)$. Werner et al. (2015) also found a reduction in IL-2 by Jurkat T cells encapsulated with polyelectrolytes (Fig. 7d).

In the case of IL-6 (Fig. 7b), at $24 \mathrm{~h}$ post-encapsulation, we found that cells encapsulated with PAH, PSS/PAH, and PSS-GNR/PAH secreted IL-6 at a significantly higher level than unencapsulated cells $(P<0.01)$. It was reported that the IL-6 secretion in encapsulated cells could be enhanced by polyelectrolytes used for encapsulation (Mooranian et al. 2016). Based on our results here, an induction in IL-6 levels was significantly detected in PAH@Jurkat cells at $5 \mathrm{~h}$ post-encapsulation. This implies that the PAH layer could first impact IL-6 induction. After cells were encapsulated with the second layer, higher levels of IL-6 were detected. Thus, the second layer of PSS or PSS-GNRs could also be involved in triggering an immune response related to IL-6 expression. Furthermore, the second layer of encapsulation might lead to a decrease in porosity that could cause an accumulation of metabolic byproducts related to IL-6 production (Mooranian et al. 2016; Schmidt et al. 2008).

\section{Biological activity in co-culture between macrophage cells and Jurkat $T$ cells encapsulated with polyelectrolytes and PSS-coated GNRs}

It is well known that macrophage cells play an important role in the immune system. Because of the lack of information on biological activities between encapsulated cells and macrophages, we were therefore interested in the biological activities of these two cells in co-culture. The co-culture system of macrophages and $\mathrm{T}$ cells can be used to acquire more information on immune responses between encapsulated $\mathrm{T}$ cells and macrophages.

We used non-activated Jurkat T cells, with and without encapsulation, to investigate whether the encapsulation of cells could influence inflammatory cytokine enhancement in the co-culture system between human macrophages and human T cells. Here, we only focused on the investigation of the double layer encapsulation (PSS/PAH@Jurkat \& PSS-GNR/PAH@Jurkat cells) because we aim to use PSSGNR/PAH@Jurkat cells in a future study for therapeutic applications. The ratio of THP-1 macrophage per Jurkat T cell used in the co-culture system was 1:1. The results showed that there were no significant differences in IL-2 and IL-1 $\beta$ expression in THP-1 macrophage and Jurkat T cell co-cultures when both encapsulated and unencapsulated Jurkat T cells were used (Fig. 8c, d). This implies that there was no cell-contact-mediated activation of THP-1 macrophages by encapsulated and unencapsulated Jurkat $\mathrm{T}$ cells. As stated previously, TNF- $\alpha$ and IL- 6 cytokines are inflammatory cytokines and they may be involved in some disease pathogenesis (Rossol et al. 2005). Therefore, it was also worthwhile to test whether encapsulated cells could lead to induction of IL-6 and TNF- $\alpha$ expression.

Our results showed that there was a significant induction of TNF- $\alpha$ in THP-1 macrophages/unencapsulated Jurkat T cells after co-culturing for $24 \mathrm{~h}$ when compared with THP1 macrophages cultured alone. However, there was no increase in TNF- $\alpha$ level when THP-1 macrophages were cultured with encapsulated Jurkat T cells (PSS/PAH@ Jurkat or PSS-GNR/PAH@Jurkat) (Fig. 8b). These results

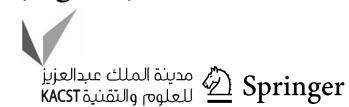


Fig. 7 Different proinflammatory responses of TNF$\alpha(\mathbf{a}), \mathrm{IL}-6$ (b), IL-1 $\beta$ (c), and IL-2 (d) from each type of encapsulated and unencapsulated cells at 5 and $24 \mathrm{~h}$ post-encapsulation. * Significant difference in proinflammatory responses at $P<0.01$ compared with unencapsulated cells at $5 \mathrm{~h}$ and $\neq$ at $24 \mathrm{~h}$. Statistical analysis was performed by TukeyKramer test $(n \geq 4)$
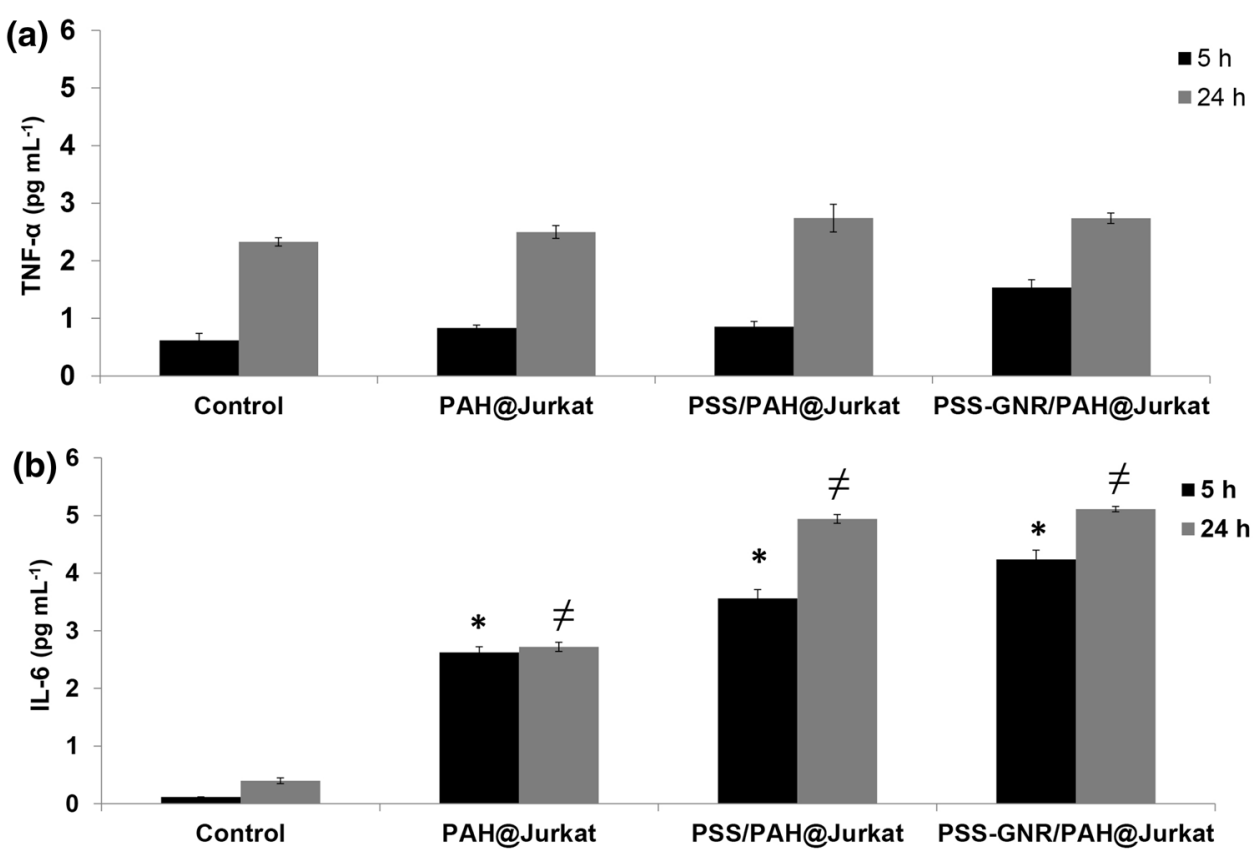

(c) 6
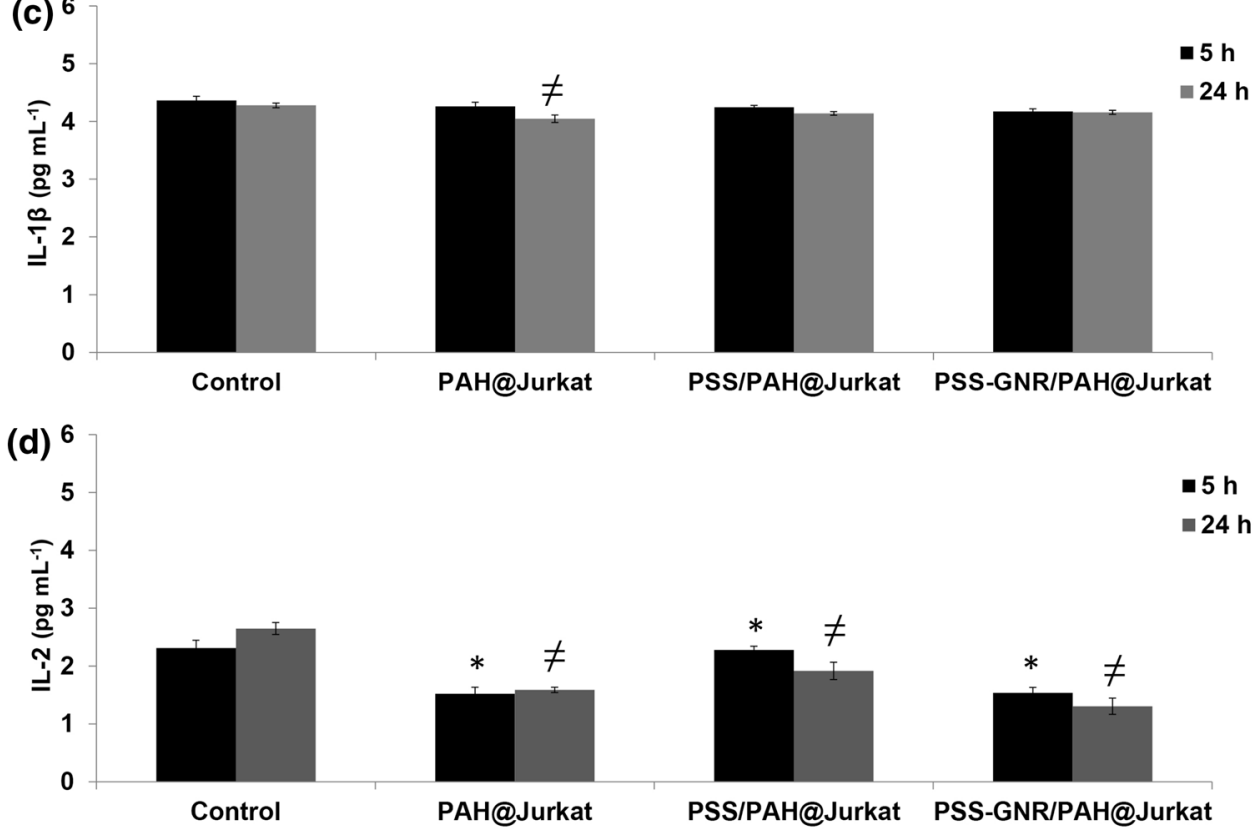

indicate that the encapsulation of Jurkat $\mathrm{T}$ cells could help prevent the induction of TNF- $\alpha$ production through cellcontact-mediated activation of THP-1 macrophages by Jurkat $\mathrm{T}$ cells. The layer of PSS/PAH or PSS-GNR/PAH could block the ligand interactions involved in TNF- $\alpha$ production by THP-1 macrophages resulting in no activation of the THP- 1 macrophages to enhance TNF- $\alpha$ production. The TNF- $\alpha$ levels in co-cultures of THP-1 macrophages with PSS/PAH@Jurkat or PSS-GNR/ PAH@Jurkat cells were similar. This implies that GNRs had no impact on inducing TNF- $\alpha$. These two types of cell encapsulation resulted in different zeta potential values
$(-21.1 \pm 0.4$ for PSS/PAH@Jurkat and $-11.3 \pm 0.4$ for PSS-GNR/PAH@Jurkat cells), but it seems that the different degree of zeta potential values did not impact on the induction of TNF- $\alpha$ in our system.

In the case of IL-6 expression, we found that there was no significant difference in IL-6 production of THP-1 macrophage/Jurkat $\mathrm{T}$ cell (both unencapsulated and encapsulated cells) co-cultures. These results also revealed that there was no cell-contact-mediated activation of THP1 macrophages through ligand interactions by encapsulated and unencapsulated Jurkat T cells (Fig. 8a). However, it is worth noting that though, there was an induction of IL- 6 in 
Fig. 8 The expression of inflammatory cytokines IL-6 (a), TNF- $\alpha$ (b), IL-1 $\beta$ (c), and IL-2 (d) in THP-1 macrophages co-cultured with unencapsulated and encapsulated Jurkat T cells. Two different types of encapsulated Jurkat T cells (PSS/PAH@Jurkat and PSSGNR/PAH@Jurkat)were used in this co-culture system.

*Significant difference in TNF- $\alpha$ level at $P<0.01$ compared with THP-1 macrophages alone.

Statistical analysis was performed by Tukey-Kramer test $(n \geq 7)$
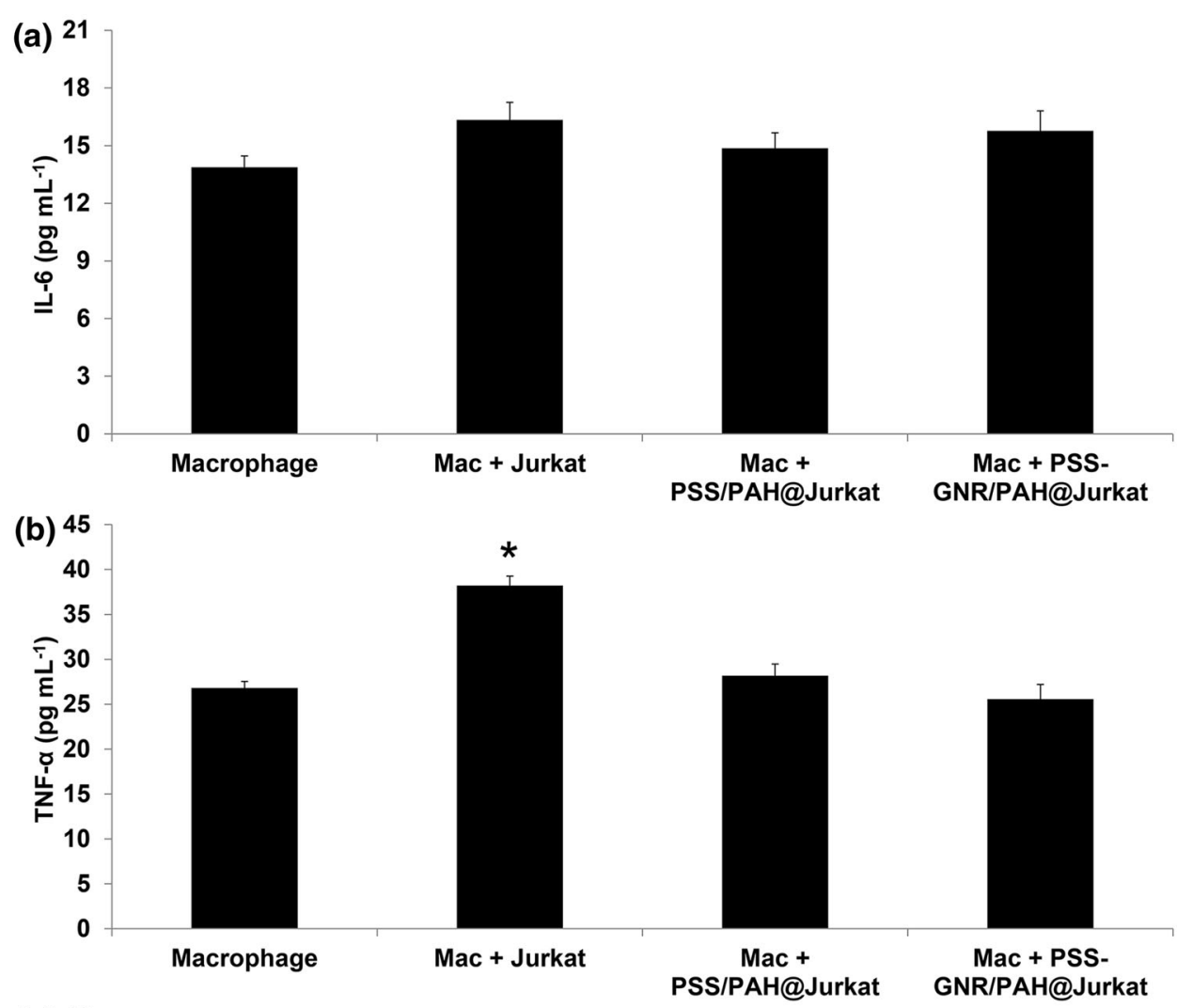

(c) 10
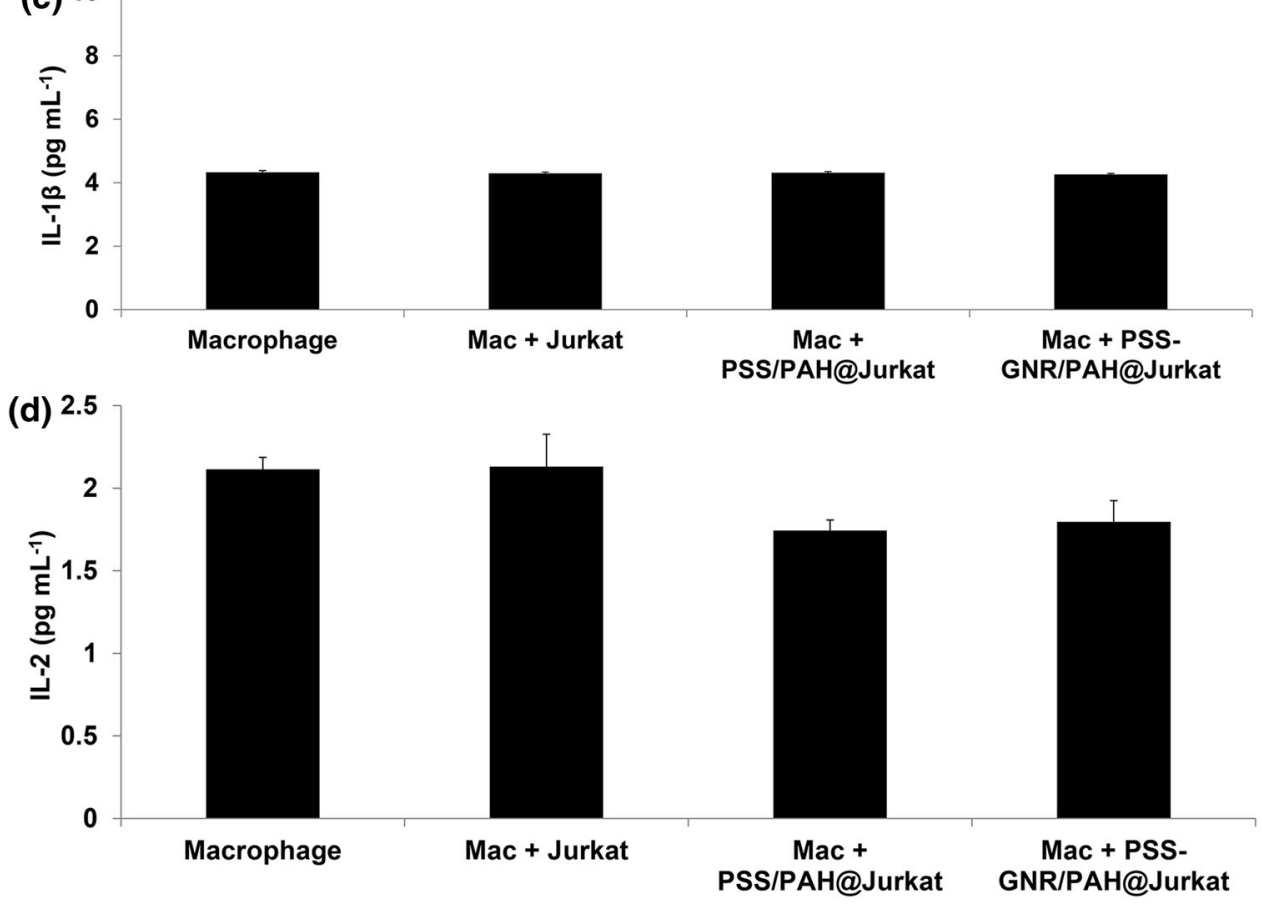

encapsulated Jurkat $\mathrm{T}$ cells. Nonetheless, the induction amount of IL-6 was much lower than Jurkat cells treated with a positive control chemical (phorbol 12-myristate 13-acetate; PMA) (Supplementary Material, Fig. S1) and there was no significant production of IL-6 in THP-1 macrophage/Jurkat $\mathrm{T}$ cell co-culture. This implies that the induction amount of IL-6 in encapsulated Jurkat T cells might be at a level that does not lead to an adverse effect. 


\section{Conclusions}

We demonstrate a single-cell encapsulation of Jurkat T cells and biological activities of cells after encapsulation. Jurkat $T$ cells were successfully encapsulated with PAH, PSS/PAH, or PSS-GNR/PAH. Encapsulated cells mostly maintained viability and their metabolic activity. This could be due to the mild interaction between PAH, PSS/PAH, or PSS-GNR/ $\mathrm{PAH}$ and the cell membrane. The cell proliferation assay confirmed that encapsulated cells were capable of cell division, and PSS-GNR/PAH@Jurkat cells had the highest cell proliferation rate. In THP-1 macrophage/Jurkat cell co-cultures, the encapsulation of Jurkat $\mathrm{T}$ cells could shield some cell surface functions that impacts cell-to-cell signaling between THP-1 macrophages and Jurkat T cells, resulting in no induction of TNF- $\alpha$ or other cytokines observed in the cocultures. Unlike the macro- or microcapsule cell encapsulation technique, cells were singly encapsulated with a thin layer of polyelectrolytes and polyelectrolyte-coated GNRs, which had no significant effect on cell size. Therefore, this technique should avoid the problem of blood flow blockage when cells are applied in a blood circulation system. As well, with the property of GNRs mentioned earlier, to combine GNRs on a layer of encapsulated cells should help increase the efficiency for diagnostic or therapeutic purposes. Overall, the assessment of biological activities found in this study suggests that the combination of polyelectrolytes and GNRs for single-cell encapsulation was reasonably biocompatible with Jurkat $\mathrm{T}$ cells and macrophages. The results from this study support continuing and further developing studies based on using this encapsulation technique, combined with GNRs, in various biomedical applications without adverse inflammatory effects.

Acknowledgements This work was fully supported by the Thailand Research Fund (TRF; RSA5880011), Mahidol University, and Faculty of Science, Mahidol University. The authors thank the Center of Nanoimaging and Center of Excellent on Environmental Health and Toxicology, Faculty of Science, Mahidol University for providing some facilities used for this research. We also thank Dr. Sujin Jiracheewanun and Mr. Pongsak Prasertphol for their technical supports.

Open Access This article is distributed under the terms of the Creative Commons Attribution 4.0 International License (http:// creativecommons.org/licenses/by/4.0/), which permits unrestricted use, distribution, and reproduction in any medium, provided you give appropriate credit to the original author(s) and the source, provide a link to the Creative Commons license, and indicate if changes were made.

\section{References}

Ai H, Jones SA, Lvov YM (2003) Biomedical applications of electrostatic layer-by-layer nano-assembly of polymers, enzymes, and nanoparticles. Cell Biochem Biophys 39:23
Antipov AA, Sukhorukov GB (2004) Polyelectrolyte multilayer capsules as vehicles with tunable permeability. Adv Colloid Interface Sci 111:49-61

Bhatia SR, Khattak SF, Roberts SC, Uludag H (2005) Polyelectrolytes for cell encapsulation. Curr Opin Colloid Interface Sci 10:45-51

Bondar OV, Saifullina DV, Shakhmaeva II, Mavlyutova II, Abdullin TI (2012) Monitoring of the zeta potential of human cells upon reduction in their viability and interaction with polymers. Acta Naturae 4:78-81

Borkowska M, Grzeczkowicz A, Strawski M, Kawiak J, Szklarczyk M, Granicka LH (2014) Performance and detection of nano-thin polyelectrolyte shell for cell coating. J Nanopart Res 16:2488

Bray D (2000) Critical point drying of biological specimens for scanning electron microscopy. Supercrit Fluid Methods Protoc 13:235-243

Cook MT, Tzortzis G, Khutoryanskiy VV, Charalampopoulos D (2013) Layer-by-layer coating of alginate matrices with chitosan-alginate for the improved survival and targeted delivery of probiotic bacteria after oral administration. J Mater Chem B $1: 52-60$

de Vos P, Lazarjani HA, Poncelet D, Faas MM (2014) Polymers in cell encapsulation from an enveloped cell perspective. Adv Drug Deliv Rev 67-68:15-34

Diaspro A, Silvano D, Krol S, Cavalleri O, Gliozzi A (2002) Single living cell encapsulation in nano-organized polyelectrolyte shells. Langmuir 18:5047-5050

Dykman LA, Khlebtsov NG (2014) Uptake of engineered gold nanoparticles into mammalian Cells. Chem Rev 14:1258-1288

Fakhrullin RF, Zamaleeva AI, Morozov MV, Tazetdinova DI, Alimova FK, Hilmutdinov AK, Zhdanov RI, Kahraman M, Culha M (2009) Living fungi cells encapsulated in polyelectrolyte shells doped with metal nanoparticles. Langmuir $25: 4628-4634$

Fakhrullin RF, Zamaleeva AI, Minullina RT, Konnova SA, Paunov VN (2012) Cyborg cells: functionalisation of living cells with polymers and nanomaterials. Chem Soc Rev 41:4189-4206

Franz B, Balkundi SS, Dahl C, Lvov YM, Prange A (2010) Layer-bylayer nano-encapsulation of microbes: controlled cell surface modification and investigation of substrate uptake in bacteria. Macromol Biosci 10:164-172

Granicka LH, Borkowska M, Grzeczkowicz A, Stachowiak R, Szklarczyk M, Bielecki J, Strawski M (2014) The targeting nanothin polyelectrolyte shells in system with immobilized bacterial cells for antitumor factor production. J. Biomed. Mater. Res. A 102:2662-2668

Gurruchaga H, Saenz del Burgo L, Ciriza J, Orive G, Hernández RM, Pedraz JL (2015) Advances in cell encapsulation technology and its application in drug delivery. Expert Opin. Drug Deliv. 12:1251-1267

Hachim D, Melendez J, Ebensperger R (2013) Nanoencapsulation of Human Adipose Mesenchymal Stem Cells: experimental Factors Role to Successfully Preserve Viability and Functionality of Cells. J. Encapsulation Adsorpt. Sci. 3:1-12

Heckman C, Kanagasundaram S, Cayer M, Paige J (2007) Preparation of cultured cells for scanning electron microscope. Nat Protoc. doi:10.1038/nprot.2007.504

Hunt NC, Grover LM (2010) Cell encapsulation using biopolymer gels for regenerative medicine. Biotechnol Lett 32:733-742

Ishihara K, Hirano T (2002) IL-6 in autoimmune disease and chronic inflammatory proliferative disease. Cytokine Growth Factor Rev 13:357-368

Juan FV, Malcolm KB, Gianpietro D (2009) Immunotherapy of human cancers using gene modified T lymphocytes. Curr Gene Ther 9:396-408

Kampf N (2002) The use of polymer for coating cells. Polym Adv Technol 13:896-905 
Kim C, Agasti SS, Zhu Z, Isaacs L, Rotello VM (2010) Recognitionmediated activation of therapeutic gold nanoparticles inside living cells. Nat Chem 2:962-966

Mooranian A, Negrulj R, Al-Salami H, Morahan G, Jamieson E (2016) Designing anti-diabetic $\beta$-cells microcapsules using polystyrenic sulfonate, polyallylamine, and a tertiary bile acid: morphology, bioenergetics, and cytokine analysis. Biotechnol Prog 32:501-509

Orive G, Santos E, Pedraz JL, Hernández RM (2014) Application of cell encapsulation for controlled delivery of biological therapeutics. Adv Drug Deliv Rev 67-68:3-14

Pandey S, Afrin F, Tripathi RP, Gangenahalli G (2013) Human T-cell line (Jurkat cell) encapsulation by nano-organized polyelectrolytes and their response assessment in vitro and in vivo. J Nanopart Res 15:1793

Pawelec G, Borowitz A, Krammer PH, Wernet P (1982) Constitutive interleukin 2 production by the Jurkat human leukemic $\mathrm{T}$ cell line. Eur J Immunol 12:387-392

Pissuwan D, Niidome T (2015) Polyelectrolyte-coated gold nanorods and their biomedical applications. Nanoscale 7:59-65

Pissuwan D, Kumagai Y, Smith NI (2013) Effect of surface-modified gold nanorods on the inflammatory cytokine response in macrophage cells. Part Part Syst Char 30:427-433

Roncarolo M-G, Battaglia M (2007) Regulatory T-cell immunotherapy for tolerance to self antigens and alloantigens in humans. Nat Rev Immunol 7:585-598

Rossol M, Kaltenhäuser S, Scholz R, Häntzschel H, Hauschildt S, Wagner U (2005) The contact-mediated response of peripheralblood monocytes to preactivated $\mathrm{T}$ cells is suppressed by serum factors in rheumatoid arthritis. Arthritis Res Ther 7:R1189R1199

Schmidt JJ, Rowley J, Kong HJ (2008) Hydrogels used for cell-based drug delivery. J Biomed Mater Res A 87A:1113-1122
Stecenko AA, King G, Torii K, Breyer RM, Dworski R, Blackwell TS, Christman JW, Brigham KL (2001) Dysregulated cytokine production in human cystic fibrosis bronchial epithelial cells. Inflammation 25:145-155

Tang A, Sharma A, Jen R, Hirschfeld AF, Chilvers MA, Lavoie PM, Turvey SE (2012) Inflammasome-mediated IL-1 $\beta$ production in humans with cystic fibrosis. PLoS One 7:e37689

Uludag H, De Vos P, Tresco PA (2000) Technology of mammalian cell encapsulation. Adv Drug Deliv Rev 42:29-64

Wang J, Shannon MF, Young IG (2006) A role for Ets1, synergizing with AP-1 and GATA-3 in the regulation of IL-5 transcription in mouse Th2 lymphocytes. Int Immunol 18:313-323

Werner M, Schmoldt D, Hilbrig F, Jérôme V, Raup A, Zambrano K, Hübner H, Buchholz R, Freitag R (2015) High cell density cultivation of human leukemia T cells (Jurkat cells) in semipermeable polyelectrolyte microcapsules. Eng Life Sci 15:357-367

Winky LWH, Dieter WT, Nikolaus JS, Man W, Yitshak Z (2003) Surface-chemistry technology for microfluidics. J Micromech Microeng 13:272

Zhao S, Zhang L, Han J, Chu J, Wang H, Chen X, Wang Y, Tun N, Lu L, Bai X-F, Yearsley M, Devine S, He X, Yu J (2016) Conformal nanoencapsulation of allogeneic $\mathrm{T}$ cells mitigates graft-versus-host disease and retains graft-versus-leukemia activity. ACS Nano 10:6189-6200

\section{Publisher's Note}

Springer Nature remains neutral with regard to jurisdictional claims in published maps and institutional affiliations. 